\title{
Predictive Risk Factors for Pulmonary Oxygen Transfer in Patients Undergoing Coronary Artery Bypass Grafting
}

\author{
Yoshihiro Suematsu, MD, Hajime SATO, ${ }^{1} \mathrm{MD}$, Toshiya OHTSUKA, MD, \\ Yutaka KoTSUKA, MD, Shunichi ARAKI, ${ }^{1}$ MD, and Shinichi TAKAMOTO, MD
}

SUMMARY

The ratio of arterial oxygen tension to inspired oxygen fraction $\left(\mathrm{PaO}_{2} / \mathrm{FiO}_{2}\right)$ is a useful indicator for weaning patients from mechanical ventilation and a reliable predictor of pulmonary dysfunction after cardiac surgery. The aim of this study was to elucidate the patient characteristics and variables that affect the $\mathrm{PaO}_{2} / \mathrm{FiO}_{2}$ ratio.

Between 1994-1998, 167 patients who underwent coronary artery bypass grafting (CABG) were examined retrospectively. Spearman's correlation coefficients were calculated between the $\mathrm{PaO}_{2} / \mathrm{FiO}_{2}$ ratio and intubation period, and length of ICU stay. Patients were then divided into two groups with a $\mathrm{PaO}_{2} / \mathrm{FiO}_{2}$ ratio $<350$ and $\mathrm{PaO}_{2} / \mathrm{FiO}_{2}$ ratio $\geq$ 350. Univariate analysis of the putative risk factors was performed. A logistic regression model was developed to evaluate factors that would influence the $\mathrm{PaO}_{2} / \mathrm{FiO}_{2}$ ratio.

A significant correlation was observed between the $\mathrm{PaO}_{2} / \mathrm{FiO}_{2}$ ratio and intubation period, and length of ICU stay. Univariate predictors of a $\mathrm{PaO}_{2} / \mathrm{FiO}_{2}$ ratio $<350$ were low body weight, low preoperative $\mathrm{PaO}_{2}$, long operation time, high $\mathrm{FiO}_{2}$, low postoperative $\mathrm{PaO}_{2}$, history of smoking, hypertension and opening of pleura $(p<0.05)$. Excellent prediction was found with a model consisting of preoperative $\mathrm{PaO}_{2}$ and hypertension.

Conclusion: The results of this study suggest that patients with a low preoperative $\mathrm{PaO}_{2}$ or hypertension may need more careful peri- and postoperative management since these factors are closely associated with the $\mathrm{PaO}_{2} / \mathrm{FiO}_{2}$ ratio. (Jpn Heart J 2001; 42: 143153)

Key words: $\mathrm{PaO}_{2} / \mathrm{FiO}_{2}$ ratio, $\mathrm{CABG}$

PREVIOUS investigations have demonstrated that the pulmonary function test is not useful for predicting postoperative outcome in patients undergoing coronary artery bypass grafting (CABG). ${ }^{1,2}$ Furthermore, the pulmonary function test is a relatively invasive preoperative screening procedure which is associated with considerable risk, especially for patients with unstable angina pectoris, and may

From the Departments of Cardiothoracic Surgery, and Public Health and ${ }^{1}$ Occupational Medicine, University of Tokyo, Tokyo, Japan.

Address for correspondence: Yoshihiro Suematsu, MD, Department of Cardiothoracic Surgery, University of Tokyo, 7-3-1, Hongo, Bunkyo-ku, Tokyo 113-8655, Japan.

Received for publication September 1, 2000.

Revised and accepted October 30, 2000. 
elevate hospital costs. For three decades, the ratio of arterial oxygen tension to inspired oxygen fraction $\left(\mathrm{PaO}_{2} / \mathrm{FiO}_{2}\right)$ has been a useful indicator for weaning patients from mechanical ventilation after cardiac surgery. This ratio is easy to calculate and is therefore highly valuable in clinical situations. Recently, Seki, et al. ${ }^{3)}$ showed that the $\mathrm{PaO}_{2} / \mathrm{FiO}_{2}$ ratio is a reliable predictor of the arterial / alveolar oxygen tension ratio $\left((\mathrm{a} / \mathrm{A}) \mathrm{PO}_{2}\right)$ during early postoperative management, and of pulmonary dysfunction in patients undergoing CABG. Little is known about the risk factors that predict decreased postoperative pulmonary oxygen transfer after CABG. Consequently, the aim of this study was to elucidate the patient characteristics and variables that affect the $\mathrm{PaO}_{2} / \mathrm{FiO}_{2}$ ratio.

\section{Materials ANd Methods}

Subjects: The case reports of 197 patients who underwent CABG procedures at our institution between January 1994 and December 1998 were reviewed retrospectively. Nineteen subjects were subsequently dropped because of incomplete data and 11 because of death. Consequently, the data for 167 subjects were used for the analysis. Preoperative characteristics, processes of care, and intermediate outcome were determined from the patients' charts.

Surgical procedure: Anesthesia consisted of $50 \mu \mathrm{g} / \mathrm{kg}$ intravenous fentanyl and $0.15 \mathrm{mg} / \mathrm{kg}$ intravenous pancronium for muscle relaxation (high-dose opioid anesthetic technique). All patients had radial arterial pressures monitored. Standard CABG was performed by the same group of surgeons and same group of anesthesiologists. Patients underwent a median sternotomy, with harvesting of saphenous veins and internal thoracic arteries as conduits. Myocardial protection was obtained with crystalloid and cold blood cardioplegia via the antegrade route, and systemic temperature was allowed to drift down toward $28^{\circ} \mathrm{C}$ during cardiopulmonary bypass. Hematocrit was maintained between $20 \%$ and $25 \%$, and cardiopulmonary bypass (CPB) flow was maintained between 2.0 and $2.5 \mathrm{l} / \mathrm{min} /$ $\mathrm{m}^{2}$. The mean perfusion pressure was kept at $50-60 \mathrm{mmHg}$ by the adjustment of nitroglycerin or phenylephrine infusion.

After arriving at the ICU patients were ventilated mechanically with either intermittent mandatory ventilation or the assist control mode. Shivering was treated with 25-50 mg intravenous midazolam. Persistent systemic hypertension (systemic blood pressure $>140 \mathrm{mmHg}$ ) was treated with infusion of nitroglycerin, nicardipine, or both, and adjusted to achieve a systolic arterial pressure of 90-130 mmHg. Basically, overnight mechanical ventilation and the sedation were used because it minimized episodes of respiratory insufficiency, hypertension, and decreased the myocardial oxygen demands resulting from spontaneous breathing. ${ }^{7)}$ 
The criteria for weaning from mechanical ventilation were as follows: (1) patients are awake and alert with cerebral function adequate for patient cooperation; (2) forced vital capacity $>10 \mathrm{ml} / \mathrm{kg}$; (3) spontaneous ventilation at a rate of not more than 30 breaths/min, with a good respiratory pattern; (4) arterial oxygen tension $>300 \mathrm{mmHg}, \mathrm{A}-\mathrm{a} \mathrm{DO}_{2}<350 \mathrm{mmHg}$, and Qs / Qp $<25 \%$ on an inspired oxygen fraction of 1.0 ; (5) stable hemodynamic parameters without low output syndrome, and intravenous requirement for epinephrine and norepinephrine $<0.2$ $\mu \mathrm{g} / \mathrm{kg} / \mathrm{min}$; and (6) adequate hemostasis (chest drainage $<100 \mathrm{ml}$ in $60 \mathrm{~min}$ ).

Patients were weaned from ventilatory support as soon as hemodynamic stability was established. Throughout the weaning process and after extubation, arterial blood gas analysis and pulse oximetry were monitored closely.

Data collection and definitions: Clinical variables were collected from patient records retrospectively. Emergency operation was defined as an operation that occurred within $48 \mathrm{~h}$ of coronary catheterization because of unstable symptoms not controlled by medical therapy, hemodynamic instability, or failed angioplasty. Diabetes was deemed to be present in patients receiving insulin therapy or oral medication for hypoglycemia because of documented elevation of fasting blood sugar levels. Hypertension and hyperlipidemia were considered to be present in patients with a documented history of hypertension or hyperlipidemia necessitating medical treatment. Cerebrovascular disease was considered to be present in patients with known carotid artery disease or in those with a previous carotid endoarterectomy. At the time of admission to the hospital for surgery, the patients were weighed and their height measured, and arterial blood gas analysis including $\mathrm{PaO}_{2}$ and $\mathrm{PCO}_{2}$ was performed in room air. At the time of catheterization, biplane cineangiography allowed the measurement of the left ventricular ejection fraction by planimetry. Preoperative renal disease was defined as a serum creatinine concentration $>1.5 \mathrm{mg} / \mathrm{d} l$. Smoking history, New York Heart Association (NYHA) class, and the presence of chronic obstructive pulmonary disease (COPD), tuberculosis (TB), or liver disease were determined from the clinical history.

All perioperative variables were collected from surgical records, anesthesia records, and cardiopulmonary bypass charts. An intraoperative requirement for epinephrine and norepinephrine of $>0.2 \mu \mathrm{g} / \mathrm{kg} / \mathrm{min}$ was thought to be due to perioperative heart failure.

Arterial blood gas analysis was performed for all patients just after transfer to the ICU under a respiratory rate of $20 / \mathrm{min}$ and a tidal lung volume of $10 \mathrm{ml} /$ $\mathrm{kg}$. The $\mathrm{PaO}_{2} / \mathrm{FiO}_{2}$ ratio was calculated from the results.

Statistical Methods: The relationship between the $\mathrm{PaO}_{2} / \mathrm{FiO}_{2}$ ratio and intubation period or length of ICU stay was determined by plotting a scatter plot and by calculation of Spearman's correlation coefficient. To determine the factors most 
closely related to the $\mathrm{PaO}_{2} / \mathrm{FiO}_{2}$ ratio, subjects were divided into two groups with $\mathrm{PaO}_{2} / \mathrm{FiO}_{2}$ ratio $\geq 350$ (mean: 436.7, SD: 64.8), or with $\mathrm{PaO}_{2} / \mathrm{FiO}_{2}$ ratio $<350$ (mean: 249.5, SD: 74.6). Differences in possible factors between these two groups were assessed by $t$-tests for continuous or ordinal variables (age, height, weight, serum creatinine, NYHA class, number of cases of carotid artery disease (CAD), ejection fraction, anesthesia time, operation time, extracorporeal circulation (ECC) time, aortic cross clamp (ACC) time, graft number, volume of fentanyl, lowest rectal temperature, glucose level, transfusion, bleeding) and by the Chi-square test for dichotomous variables (sex, smoking, hypertension, hyperlipidemia, TB, diabetes, insulin use, renal disease, cerebrovascular disease, LMT disease, emergency surgery, percutaneous coronary angioplasty, intraaortic balloon pumping use, re-do, re-intubation). The combination of variables which best predicted the $\mathrm{PaO}_{2} / \mathrm{FiO}_{2}$ ratio was selected by multiple logistic regression analysis.

In model building, outcome variable was the group indicator $\left(\mathrm{PaO}_{2} / \mathrm{FiO}_{2}\right.$ ratio $\geq 350=1$, while $\mathrm{PaO}_{2} / \mathrm{FiO}_{2}$ ratio $<350$ group $=0$ ), while possible factors were entered and removed in a stepwise fashion at the significance level of 0.05 .

\section{RESULTS}

The characteristics of the $167 \mathrm{CABG}$ patients are shown in Table I. A significant positive correlation was found between the $\mathrm{PaO}_{2} / \mathrm{FiO}_{2}$ ratio and intubation period $(r=0.188, p=0.016)$, as shown in Figure 1. Furthermore, the $\mathrm{PaO}_{2} /$ $\mathrm{FiO}_{2}$ ratio was also correlated with the length of ICU stay $(r=0.166, p=0.034)$, as shown in Figure 2.

The results of univariate analysis of all preoperative factors, including demographic attributes, are shown in Table II. Mean values were significantly smaller for body weight and preoperative $\mathrm{PaO}_{2}$ in the group with a $\mathrm{PaO}_{2} / \mathrm{FiO}_{2}$ ratio $<350$ than in the other group ( $p=0.020, p=0.005$, respectively). The proportion of patients with a history of hypertension and smoking was significantly larger in the group with $\mathrm{PaO}_{2} / \mathrm{FiO}_{2}$ ratio $<350(p=0.020$ vs $p=0.036)$. Among the perioperative factors, operation time was significantly longer and a larger proportion of patients had opening of the pleura in the group with $\mathrm{PaO}_{2} / \mathrm{FiO}_{2}$ ratio $<350(p=0.086$ vs $p=0.029)$.

Postoperative $\mathrm{PaO}_{2}$ was significantly lower in the group with $\mathrm{PaO}_{2} / \mathrm{FiO}_{2}$ ratio $<350(p<0.001)$. On the other hand, patients with $\mathrm{PaO}_{2} / \mathrm{FiO}_{2}$ ratio $<350$ had a statistically significant longer time to extubation and length of ICU stay than patients with $\mathrm{PaO}_{2} / \mathrm{FiO}_{2}$ ratio $\geq 350$ ( $p=0.016$ vs $p=0.034$, respectively).

Table III shows the results of logistic regression analysis. The results revealed that a combination of preoperative $\mathrm{PaO}_{2}$ and hypertension best predicts 
Table 1. Variables Evaluated

\begin{tabular}{|c|c|c|c|c|}
\hline & Factors & Range & Mean & SD \\
\hline \multirow{5}{*}{$\begin{array}{l}\text { Demographic } \\
\text { attributes }\end{array}$} & Age & $35-83$ & 62.5 & 9.31 \\
\hline & Sex (Male / Female) & & $132 / 36$ & \\
\hline & Body Height $(\mathrm{cm})$ & $141-181$ & 161.0 & 7.81 \\
\hline & Body Weight (kg) & $40-102$ & 61.6 & 10.4 \\
\hline & Smoking & & $109(65.3 \%)$ & \\
\hline \multirow[t]{20}{*}{ Preoperative factors } & HT & & $85(50.9 \%)$ & \\
\hline & HLD & & $60(35.9 \%)$ & \\
\hline & $\mathrm{PaO}_{2}$ & $55.0-115.8$ & 87.4 & 11.2 \\
\hline & $\mathrm{PCO}_{2}$ & $27.0-52.2$ & 41.4 & 29.5 \\
\hline & $\mathrm{TB}$ & & $13(7.8 \%)$ & \\
\hline & COPD & & $9(5.4 \%)$ & \\
\hline & Diabetes & & $73(43.7 \%)$ & \\
\hline & Insulin use & & $9(5.4 \%)$ & \\
\hline & Renal disease & & $13(7.8 \%)$ & \\
\hline & S-Cre & $0.4-3.9$ & 0.96 & 0.33 \\
\hline & Liver Disease & & $6(3.6 \%)$ & \\
\hline & Cerebrovascular Disease & & $18(10.8 \%)$ & \\
\hline & NYHA & $1-4$ & 2.17 & 0.79 \\
\hline & Number of CAD & $1-3$ & 2.38 & 0.7 \\
\hline & LMT Disease & & $47(28.1 \%)$ & \\
\hline & Ejection Fraction & $21-89$ & 60.8 & 13.5 \\
\hline & Emergency Operation & & $12(7.2 \%)$ & \\
\hline & PTCA & & $7(4.2 \%)$ & \\
\hline & IABP use & & $8(4.8 \%)$ & \\
\hline & Re-do & & $4(2.4 \%)$ & \\
\hline \multirow[t]{14}{*}{ Perioperative factors } & Anesthesia Time (hrs) & $6.3-18.6$ & 10.5 & 2.44 \\
\hline & Op Time $(\mathrm{hrs})$ & $4.3-16.3$ & 8.64 & 2.34 \\
\hline & ECC Time (min) & $84-503$ & 222.9 & 77.5 \\
\hline & ACC Time (min) & $29-241$ & 102.3 & 41.2 \\
\hline & Graft Number & $1-5$ & 2.67 & 0.94 \\
\hline & Volume of Fentanyl $(\mathrm{m} l)$ & $5.5-140$ & 62.7 & 27.9 \\
\hline & Lowest Rectal Temp $\left({ }^{\circ} \mathrm{C}\right)$ & $18.1-30.5$ & 25.1 & 2.60 \\
\hline & Glucose Level & $140-760$ & 271.2 & 78.7 \\
\hline & Transfusion $(\mathrm{m} l)$ & $0-7800$ & 924.4 & 1231 \\
\hline & IMA use & & $117(70.1 \%)$ & \\
\hline & Opening of Pleura & & $97(58.1 \%)$ & \\
\hline & Bleeding $(\mathrm{m} l)$ & $0-6650$ & 702.9 & 712.2 \\
\hline & Heart Failure & & $27(16.2 \%)$ & \\
\hline & IABP insertion & & $29(17.4 \%)$ & \\
\hline \multirow[t]{5}{*}{ Postoperative factors } & $\mathrm{FiO}_{2}$ & $50-100$ & 81.3 & 10.9 \\
\hline & $\mathrm{PaO}_{2}$ & $86.5-497.5$ & 273.5 & 92.3 \\
\hline & $\mathrm{PaO}_{2} / \mathrm{FiO}_{2}$ & $86.5-604.7$ & 341.9 & 116.9 \\
\hline & Extubation Time (hrs) & $1-457$ & 49.2 & 74.1 \\
\hline & ICU stay (day) & $1-43$ & 5.29 & 5.85 \\
\hline
\end{tabular}

$(\mathrm{N}=167)$

HT = hypertension; HLD = hyperlipidemia; TB = tuberculosis; COPD = chronic obstructive pulmonary disease; S-Cre $=$ serum creatinine; NYHA = New York Heart Association; $\mathrm{CAD}=$ coronary artery disease; LMT = left main trunk; PTCA = percutaneous coronary angioplasty; IABP = intraaortic balloon pumping; $\mathrm{Op}=$ operation; $\mathrm{ECC}=$ extracorporeal circulation; $\mathrm{ACC}=$ aortic cross-clamp; IMA = internal mammary artery. 


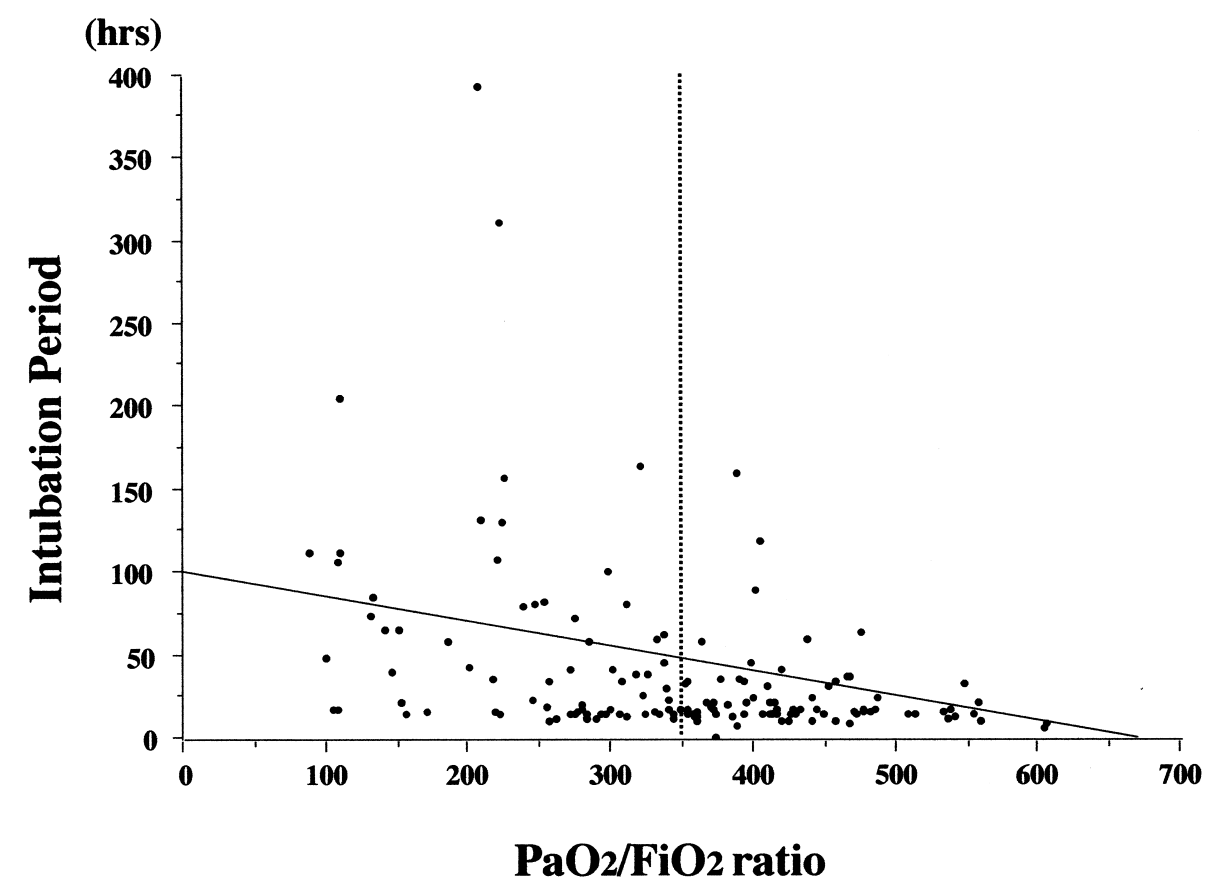

Figure 1. Correlation between the $\mathrm{PaO}_{2} / \mathrm{FiO}_{2}$ ratio and intubation period. $\mathrm{Y}=99.715-0.149 * \mathrm{X} ; \mathrm{R}=0.188$.

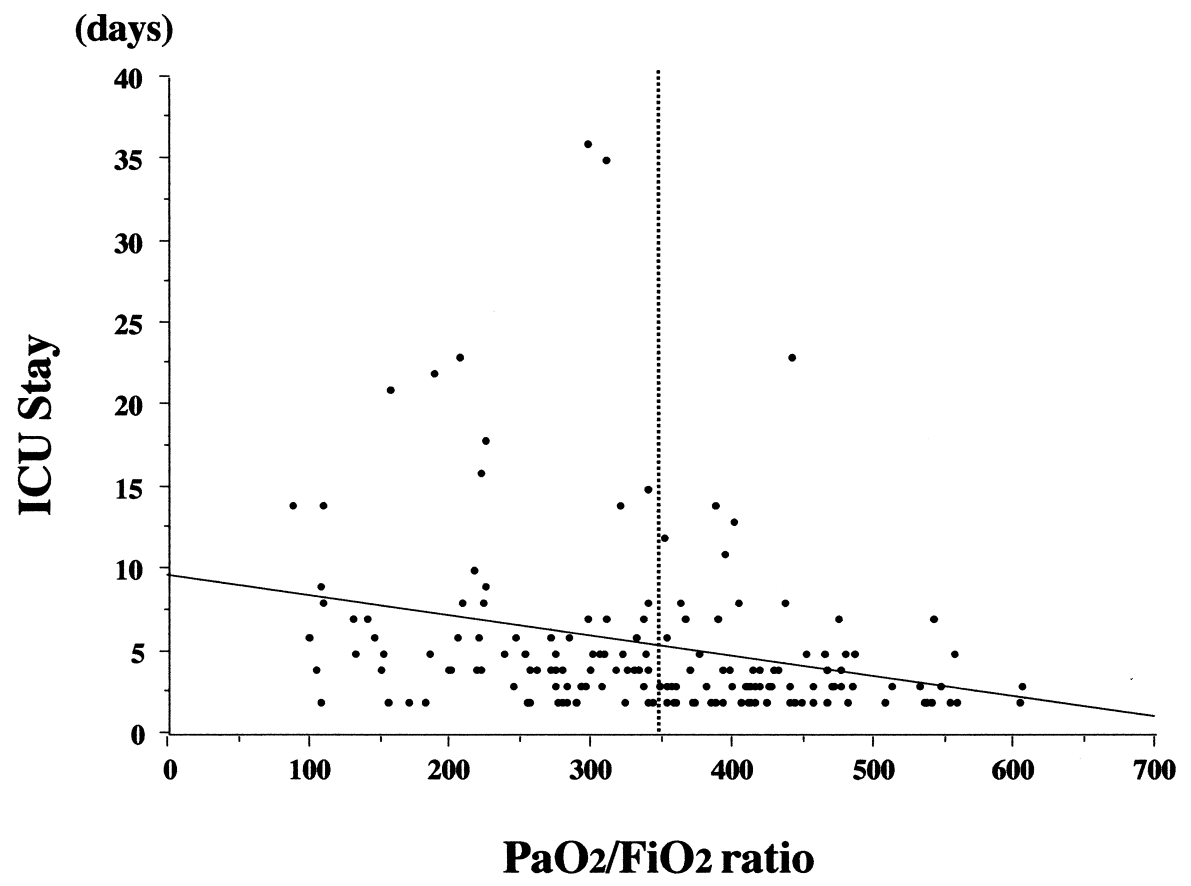

Figure 2. Correlation between the $\mathrm{PaO}_{2} / \mathrm{FiO}_{2}$ ratio and length of $\mathrm{ICU}$ stay. $\mathrm{Y}=9.6-0.012 * \mathrm{X} ; \mathrm{R}=0.166$. 
Table II. Results of Univariate Analysis of Pre-, Peri-, and Postoperative Factors in Patients with a $\mathrm{PaO}_{2} / \mathrm{FiO}_{2}$ Ratio $<350$ and those with $\mathrm{PaO}_{2} / \mathrm{FiO}_{2}$ ratio $\geq 350$

\begin{tabular}{llcrr}
\hline \multicolumn{1}{c}{ Factors } & $\begin{array}{c}\mathrm{PaO}_{2} / \mathrm{FiO}_{2} \text { ratio }<350 \\
(\mathrm{~N}=81)\end{array}$ & $\begin{array}{c}\mathrm{PaO}_{2} / \mathrm{FiO}_{2} \text { ratio } \geq 350 \\
(\mathrm{~N}=86)\end{array}$ & $p$ value \\
& & $59.8 \pm 9.70$ & $63.5 \pm 10.8$ & 0.020 \\
\hline \multirow{2}{*}{ Preoperative Factors } & Body Weight & $37(43 \%)$ & $21(25.9 \%)$ & 0.020 \\
& Smoking & $48(59.3 \%)$ & $37(43.0 \%)$ & 0.036 \\
& Hypertension & $84.9 \pm 11.2$ & $90.2 \pm 10.6$ & 0.005 \\
& $\mathrm{PaO}_{2}$ & $8.96 \pm 2.33$ & $8.34 \pm 2.31$ & 0.086 \\
& Operation Time (hrs) & $54(66.7 \%)$ & $43(50.0 \%)$ & 0.029 \\
& Opening of Pleura & $83.8 \pm 10.3$ & $78.7 \pm 11.0$ & 0.003 \\
Perioperative Factors & $\mathrm{FiO}_{2}$ & $205.9 \pm 60.1$ & $342.8 \pm 63.7$ & $<0.001$ \\
& $\mathrm{PaO}_{2}$ & $63.3 \pm 79.6$ & $35.5 \pm 66.0$ & 0.016 \\
& Intubation Time (hrs) & $6.27 \pm 6.22$ & $4.34 \pm 5.33$ & 0.034 \\
\hline
\end{tabular}

Table III. Results of Logistic Regression Analysis which Best Predict Whether a Subject would have a $\mathrm{PaO}_{2} / \mathrm{FiO}_{2}$ Ratio $<350$ or Not

\begin{tabular}{lcc}
\hline Dependent Variables *1 & (Pseudo R2, $p$ value) & Selected Variables (Odds ratio, $p$ value, 95\% CI) \\
\hline$\left(\mathrm{PaO}_{2} / \mathrm{FiO}_{2}\right.$ ratio $\left.<350\right)=0$ & $(0.063,0.002)$ & $\mathrm{PaO}_{2}(0.651,0.012,0.467-0.908)$ \\
$\left(\mathrm{PaO}_{2} / \mathrm{FiO}_{2}\right.$ ratio $\left.\geqq 350\right)=1$ & & $\mathrm{HT}(2.06,0.042,1.027-4.138)$ \\
\hline
\end{tabular}

*1. Variables are listed in Table I. Odds ratio was calculated for $10 \mathrm{mmHg}$ increase in $\mathrm{PaO}_{2}$.

whether a patient will have $\mathrm{PaO}_{2} / \mathrm{FiO}_{2}$ ratio of $<350$ or not. Forward and backward selections produced the same result.

\section{DISCUSSION}

Despite the fact that little is known about the factors responsible for decreased postoperative pulmonary oxygen transfer after $\mathrm{CABG}$, arterial blood gas analysis is used in most institutions for the management of patients who need mechanical ventilatory support after cardiac surgery. The aim of this study was to elucidate the patient characteristics and operative variables for the $\mathrm{PaO}_{2} / \mathrm{FiO}_{2}$ ratio.

For three decades, the (a/A) $\mathrm{PO}_{2}$ has been extremely useful when making decisions on weaning patients from mechanical ventilation after cardiac surgery. The $\mathrm{PaO}_{2} / \mathrm{FiO}_{2}$ ratio is easier to calculate, and may be more valuable in clinical situations. In 1983, Covelli, et al. ${ }^{4)}$ demonstrated that oxygen tension-based indi- 
ces, including both (a / A) $\mathrm{PO}_{2}$, and $\mathrm{PaO}_{2} / \mathrm{FiO}_{2}$, were highly reliable, even in critically ill patients, if the cardiac index was within the normal range of 2.5-5.0 $\mathrm{l} /$ $\mathrm{min} / \mathrm{m}^{2}$ or if the (a-A) $\mathrm{PO}_{2}$ was between 3.3 and $6.0 \mathrm{ml} / \mathrm{d} l$. In a recent study to determine the effects of diabetes on pulmonary gas exchange in patients undergoing CABG, Seki, et al. reported correlation coefficients of 0.90 for the $\mathrm{PaO}_{2} /$ $\mathrm{FiO}_{2}$ ratio, 0.81 for (a/A) $\mathrm{PO}_{2}$, and 0.68 for (a-A) $\mathrm{PO}_{2}$; even when the cardiac index was low, the $r$ value for the $\mathrm{PaO}_{2} / \mathrm{FiO}_{2}$ ratio was 0.76 , ${ }^{3,5)}$ They also concluded that the $\mathrm{PaO}_{2} / \mathrm{FiO}_{2}$ ratio was a reliable predictor of the (a/A) $\mathrm{PO}_{2}$ ratio during early postoperative management, and also of pulmonary dysfunction in patients undergoing CABG. In the present study, the $\mathrm{PaO}_{2} / \mathrm{FiO}_{2}$ ratio was correlated with intubation period and length of ICU stay, with $r$ values of 0.188 and 0.166 , respectively.

Postoperative ventilation of patients undergoing cardiac surgery was justified because the incidence of respiratory insufficiency or low cardiac output after cardiac surgery was relatively high. ${ }^{6,7)}$ High dose opioid anesthesia has been used universally in cardiac surgery. However, there are many adverse effects of mechanical ventilation. Prolonged mechanical ventilation increases hospital costs, nursing dependency, airways and lung trauma, as well as stress and discomfort of endotracheal suctioning and weaning from ventilation. ${ }^{8-10)}$ More recently, a combination of modified anesthetic techniques, and advances in surgical procedures including myocardial protection and postoperative management has resulted in a marked decrease in postoperative intubation period. ${ }^{11,12)}$ Cheng, et $a l .{ }^{13)}$ demonstrated that early extubation could be performed safely and did not increase perioperative morbidity.

In the present study, univariate analysis showed that preoperative factors of body weight, smoking history, hypertension, preoperative $\mathrm{PaO}_{2}$ and operation time, and perioperative factors of opening of pleura influenced the $\mathrm{PaO}_{2} / \mathrm{FiO}_{2}$ ratio. Unexpectedly, there were no significant differences in age, renal disease, brain disease, ejection fraction or emergency surgery between the groups with different $\mathrm{PaO}_{2} / \mathrm{FiO}_{2}$ ratios. Moreover, anesthesia time, ECC time, ACC time, volume of fentanyl, rectal temperature, perioperative heart failure, and volume of transfusion did not differ between the two groups. Logistic regression analysis revealed that a combination of preoperative $\mathrm{PaO}_{2}$ and hypertension was a good predictor of the $\mathrm{PaO}_{2} / \mathrm{FiO}_{2}$ ratio. Once adjusted for these factors, no other preoperative or perioperative factors were incorporated into the model as independent predictors.

The relationship between hypertension and the $\mathrm{PaO}_{2} / \mathrm{FiO}_{2}$ ratio remains unclear although there are two possibilities: (1) splanchnic hypoperfusion. It is thought that cardiopulmonary bypass itself causes endothelial cell damage through activation of the coagulation system, complement, the fibrinolytic sys- 
tem, white blood cells and other inflammatory mediators such as cytokines. ${ }^{14,15)}$ Some investigators have suggested that a low postoperative cardiac output state gives rise to splanchnic hypoperfusion and mucosal ischemia which results in the translocation of endotoxins from the intestine into the circulation. ${ }^{16-18)}$ Recently, Christenson, et al ${ }^{19)}$ showed that hypertension was one of the independent risk factors for adult respiratory distress syndrome, characterized by high permeability pulmonary edema caused by endothelial damage. Patients with chronic hypertension are liable to develop hypoperfusion during CABG under ordinary pressure control. Systemic hypoperfusion may cause endothelial cell damage resulting in refractory hypoxia which shows a low $\mathrm{PaO}_{2} / \mathrm{FiO}_{2}$ ratio; and (2) another possibility is changes in the vascular endothelium and its function. It is generally accepted that the endothelium serves numerous functions such as permeability, transport of blood-borne substances, and biotransformation of numerous agents present in plasma. ${ }^{20)}$ In addition, endothelial cells are thought to sense shear stress, flow, pressure, injury, and $\mathrm{PaO}_{2}$. Several studies have demonstrated that acute elevations in blood pressure and chronic hypertension increase the permeability of the endothelium, promoting movement of high and low molecular weight substances and changed compounds from the vascular lumen. ${ }^{21,22)}$ The influence of $\mathrm{CABG}$ on endothelium altered by hypertension is not yet understood. However, these changes may result in pulmonary edema, compared with patients without hypertension.

Preoperative $\mathrm{PaO}_{2}$ was another independent determinant of the $\mathrm{PaO}_{2} / \mathrm{FiO}_{2}$ ratio and this warrants further investigation. It is known that severe pulmonary complications after CABG are more likely to occur in patients with COPD, which has largely been regarded as a risk factor for early mortality. ${ }^{23)}$ Charles, et al. ${ }^{24)}$ demonstrated that COPD was associated with increased length of ICU stay and hospital stay, irrespective of the patient's age. A preoperative forced expiratory volume in $1 \mathrm{sec}$ significantly affected hospital stay in patients $<70$ years of age $(p=0.0001)$. Furthermore, the 5 -year survival after CABG was influenced significantly by the level of preoperative forced expiratory volume in $1 \mathrm{sec}$. On the other hand, Zibrak and O'Donnell ${ }^{1}$ showed that static pulmonary function tests have limited sensitivity and specificity to assess the risk of respiratory complications after $\mathrm{CABG}$, and recently Jacob, et al. ${ }^{2}$ ) also concluded that pulmonary function tests were not useful in predicting postoperative outcome in patients undergoing CABG. Unfortunately, the results of pulmonary function tests were not used for analysis in this study due to incomplete data. In our hospital not all patients had routine screening preoperative pulmonary function tests, because these elevate hospital costs and are sometimes not advisable, especially for patients with unstable angina pectoris. 
In conclusion, the results of the present study suggest that patients with poor preoperative $\mathrm{PaO}_{2}$ or hypertension may need more careful peri- and postoperative management since these factors are closely associated with the $\mathrm{PaO}_{2} / \mathrm{FiO}_{2}$ ratio.

\section{REFERENCES}

1. Zibrak JD, O'Donnell CR. Indications for preoperative pulmonary function testing. Clin Chest Med 1993; 14: 227-36.

2. Jacob B, Amoateng-Adjepong Y, Rasakulasuriar S, Manthous CA, Haddad R. Preoperative pulmonary function tests do not predict outcome after coronary artery bypass. Conn Med 1997; 61: 327-32.

3. Seki S, Yoshida H, Ooba O, Teramoto S, Komoto Y. Pulmonary oxygen transfer deficits of diabetic origin in patients undergoing coronary artery bypass grafting. Surg Today 1993; 23: 592-7.

4. Covelli HD, Nessan VJ, Tuttle WK. Oxygen derived variables in acute respiratory failure. Crit Care Med 1983; 11: 646-9.

5. Seki S, Yoshida H, Momoki Y, Ooba O, Teramoto S, Komoto Y. Impaired pulmonary oxygenation of diabetic origin in patients undergoing coronary artery bypass grafting. Cardiovasc Surg 1993; 1: 72-8.

6. Shapiro BA, Lichtenthal PR. Inhalation-based anesthetic techniques are the key to early extubation of the cardiac surgical patient. Cardiothorac Vasc Anesth 1993; 7: 135-6.

7. Lefemine AA, Harken DE. Postoperative care following open-heart operations: routine use of controlled ventilation. J Thorac Cardiovasc Surg 1966; 52: 207-16.

8. Chong JL, Pillai R, Fisher A, Grebenik C, Sinclair M, Westaby S. Cardiac surgery: moving away from intensive care. Br Heart J 1992; 68: 430-3.

9. Quasha AL, Loeber N, Feeley TW, Ullyot DJ, Roizen MF. Postoperative respiratory care: a controlled trial of early and late extubation following coronary-artery bypass grafting. Anesthesiology 1980; 52: 135-41.

10. Higgins TL. Pro:early endotracheal extubation is preferable to late extubation in patients following coronary artery surgery. J Cardiothorac Vasc Anesth 1992; 6: 488-93.

11. Butler J, Chong GL, Pillai R, Westaby S, Rocker GM. Early extubation after coronary artery bypass surgery: effects on oxygen flux and haemodynamic variables. J Cardiovasc Surg (Torino) 1992; 33: 276-80.

12. Royse CF, Royse AG, Soeding PF. Routine immediate extubation after cardiac operation: a review of our first 100 patients. Ann Thorac Surg 1999; 68: 1326-9.

13. Cheng DC, Karski J, Peniston C, et al. Morbidity outcome in early versus conventional tracheal extubation after coronary artery bypass grafting: a prospective randomized controlled trial. J Thorac Cardiovasc Surg. 1996; 112: 755-64.

14. Westaby S. Organ dysfunction after cardiopulmonary bypass. A systemic inflammatory reaction initiated by the extracorporeal circuit. Intensive Care Med 1987; 13: 89-95.

15. Kirklin JK. Prospects for understanding and eliminating the deleterious effects of cardiopulmonary bypass. Ann Thorac Surg 1991; 51: 529-31.

16. Baue AE. The role of the gut in the development of multiple organ dysfunction in cardiothoracic patients. Ann Thorac Surg 1993; 55: 822-9.

17. Ohri SK, Desai JB, Gaer JA, et al. Intraabdominal complications after cardiopulmonary bypass. Ann Thorac Surg 1991; 52: 826-31.

18. Krasna MJ, Flancbaum L, Trooskin SZ, et al. Gastrointestinal complications after cardiac surgery. Surgery 1988; 104: 773-80.

19. Christenson JT, Aeberhard JM, Badel P, et al. Adult respiratory distress syndrome after cardiac surgery. Cardiovasc Surg 1996; 4: 15-21.

20. Peach MJ, Loeb AL. Changes in vascular endothelium and its function in systemic arterial hypertension. Am J Cardiol 1987; 60: 1101-51.

21. Goldby FS, Beilin LJ. Relationship between arterial pressure and the permeability of arterioles to carbon particles in acute hypertension in the rat. Cardiovasc Res 1972; 6: 384-90. 
22. Majack RA, Bhalla RC. Endothelial alterations and colloidal carbon permeability in the peripheral vasculature of the spontaneously hypertensive rat. Exp Mol Pathol 1980; 32: 201-15.

23. Cohen A, Katz M, Katz R, Hauptman E, Schachner A. Chronic obstructive pulmonary disease in patients undergoing coronary artery bypass grafting. J Thorac Cardiovasc Surg 1995; 109: 574-81.

24. Canver CC, Nichols RD, Kroncke GM. Influence of age-specific lung function on survival after coronary bypass. Ann Thorac Surg 1998; 66: 144-7. 